\title{
A vez dos independentes(?): um olhar sobre a produção musical independente do país
}

\author{
Eduardo Vicente 1 \\ Universidade de São Paulo
}

\begin{abstract}
Resumo: Esse texto pretende discutir o desenvolvimento da produção musical independente no Brasil a partir da análise daqueles que considero seus três principais momentos de articulação: a cena do final dos anos 7o, marcada pela atuação do músico e produtor Antonio Adolfo e pela produção desenvolvida em torno do Teatro Lira Paulistana (Sâo Paulo), a cena dos anos 9o, impulsionada pelo desenvolvimento das tecnologias digitais de produção e pelas estratégias de terceirização das grandes gravadoras e o momento atual, de inédita articulação da cena independente bem como de sua atuação autônoma em diversos segmentos musicais.
\end{abstract}

Palavras-chave: música independente; música popular; indústria fonográfica.

\begin{abstract}
This paper aims at discussing the development of Brazilian independent musical production, throughout the analysis of what I consider its three main points of articulation: the late 7o's scene, which was marked by the actuation of the musician and producer Antonio Adolfo and by the production that emerged from Lira Paulistana theater (São Paulo); the 9o's scene, that was boasted by the evolution of the digital technologies for production and the Majors' outsourcing strategies; and the present moment of a never seen articulation of the independent scene, as well its autonomous performance in different musical segments.
\end{abstract}

Keywords: independent music; popular music; phonographic industry.

Resumen: Este texto pretende discutir el desarrollo de la producción musical independiente en el Brasil, a partir del análisis de aquellos que considero sus tres principales momentos de articulación: la escena del final de los años 70 , marcada por la actuación del músico y productor Antonio Adolfo y por la producción desarrollada en vuelta del Teatro Lira Paulistana (São Paulo), la escena de los años 9o, impulsada por el desarrollo de las tecnologías digitales de producción y por las estrategias de tercerización de las grandes disqueras y el momento actual, de inédita articulación de la escena independiente bien como de su actuación autónoma en diversos segmentos musicales.

Palabras llave: música independiente; música popular; indústria fonográfica. 
Résumé: Ce texte prétend discuter du développement de la production musicale indépendante au Brésil, à partir de l'analyse de ceux que je considère comme ses trois principaux moments d'articulation: le scénario de la fin des années 70, marqué par le travail du musicien et producteur Antonio Adolfo et par la production developpée autour du Teatro Lira Paulistana (à São Paulo); le scénario des années 9o, influencé par le développement des technologies digitales de production et par les stratégies de sous-traitance des grands labels du disque; et le moment actuel, $d$ 'articulation inédite du scénario indépendant, ainsi que de son action autonome dans les divers segments musicaux.

Mots-clés: musique indépendante, musique populaire, industrie phonographique

No presente artigo, pretendo discutir o desenvolvimento da produção musical independente no país bem como seu momento atual, marcado tanto por uma crise generalizada da indústria quanto por uma inédita organização da cena independente. Essa crise, que se vincula ao contexto geral da economia e a fatores específicos da indústria (como a pirataria digital e de formatos), parece estar afetando a capacidade das grandes gravadoras de atuar nos múltiplos segmentos do mercado, ampliando assim os espaços para a produção independente.

Mas antes, convém situar essa diferenciação entre as empresas. Seguindo a tradição norte-americana, denomino aqui como majors às gravadoras de atuação globalizada e/ou ligadas aos grandes conglomerados de comunicação existentes no país. Essas empresas tendem a operar com a difusão maciça de alguns poucos artistas e álbuns (blockbusters), baseando sua estratégia de atuação na integração sinérgica entre áudio e vídeo que a forma conglomerado lhes possibilita. Atualmente, esse grupo é formado pelas empresas transnacionais Universal (França), Warner (EUA), Sony/BMG (Japão/Alemanha) e EMI (Inglaterra), além da nacional Som Livre².

\footnotetext{
2 A Warner e a EMI, única empresa de atuação única dessa relação, estiveram envolvidas durante o ano de 2006 numa (aparentemente) frustrada tentativa de fusão que reduziria a três o número de majors transnacionais do setor. A Som Livre é o braço fonográfico da Rede Globo e foi criada em 1971 para o
} 
Dentro dessa mesma tradição, o termo indies refere-se às empresas de atuação predominantemente local, vinculadas normalmente a segmentos musicais específicos, que costumam atuar na formação de novos artistas e na prospecção de novos nichos de mercado. Porém, considerando a pulverização dos meios de produção musical que as tecnologias digitais passaram a proporcionar já a partir do final dos anos 80 , entendo que hoje o termo se refere indistintamente tanto a pequenas gravadoras quanto a artistas que desenvolvem autonomamente a produção de seus discos.

\section{Os $\operatorname{anos} 70 / 80$}

Embora alguns autores citem experiências anteriores envolvendo a produção musical independente no pais ${ }^{3}$ considero o disco "Feito em Casa" (1977), de Antônio Adolfo, como um marco fundamental, já que foi a partir de seu lançamento que - pela primeira vez - desenvolveu-se uma discussão em torno do tema.

O momento de seu surgimento marca o final de uma longa trajetória de crescimento e organização da indústria do disco no país que, segundo dados da ABPD (Associação Brasileira de Produtores de Discos), teve sua produção quase decuplicada entre os anos de 1966 e 1979, ao mesmo tempo em que as principais empresas internacionais do setor iniciavam ou ampliavam sua atuação no país ${ }^{4}$.

Além disso, a indústria era fortemente favorecida pela lei de incentivos fiscais Disco é Cultura, que permitia às empresas "abater do montante do Imposto de Circulação de Mercadorias os direitos comprovadamente pagos a autores e artistas domiciliados no país" (Idart, 1980: 118). Isso ampliava tanto a sua margem de lucro como o seu fôlego para investir em artistas nacionais.

\footnotetext{
lançamento das trilhas de novelas da emissora. Por essa razão, ela tradicionalmente não contrata ou lança artistas individuais (sendo Xuxa a principal exceção a essa regra).

3 Um caso frequentemente citado é o do LP Paêbirú, de Lula Cortes e Zé Ramalho, de 1972, que foi gravado nos estúdios da Rozemblit e lançado pela Abrakadabra Produções Artísticas. Disco Independentes $S / A$, Jornal do Brasil, 01/07/1981. Já José Ramos Tinhorão, cita os selos criados por Severio Leonetti e João Gonzaga ainda na década de 10. A onda dos independentes, Jornal do Brasil, 30/08/1980.

4 Ofereço uma visão mais detalhada desse cenário em Organização, Crescimento e Crise: a indústria fonográfica brasileira nas décadas de 60 e 70. In: Revista de Economía Política de las Tecnologias de la Información y Comunicación. www.eptic.com.br. Vol. VIII, N. 3, sep-dic. 2006, p. 114-128.
} 
Porém, a crise que já se desenhava ao final dos anos 70, e que afetaria profundamente o setor já no início da década seguinte ${ }^{5}$, muda completamente esse cenário: a indústria aumenta sua seletividade, racionaliza sua atuação, reduz seus elencos e, nesse processo, tende a marginalizar artistas menos imbuídos de sua lógica ou não classificáveis dentro dos segmentos de mercado que passa a privilegiar. Nesses termos, uma cena independente surge tanto como espaço de resistência cultural e política à nova organização da indústria, quanto como única via de acesso ao mercado para um variado grupo de artistas. Essa contradição tenderá, inclusive, a alimentar todo o debate desenvolvido no período. Helio Ziskind e Lelo Nazario - músicos profundamente envolvidos com essa produção - sintetizaram bem essas posições

Escrevendo para a Folha de São Paulo em 14/03/1982, Ziskind busca desmistificar o movimento independente afirmando que:

Não se pode dizer que a música veiculada por um disco independente não possa ser registrada por uma gravadora. Como também não se pode dizer que um determinado disco não precisava ser independente. Não há uma relação de necessidade entre música e disco independente... Ser independente não é qualidade musical, pode ser apenas uma contingência ${ }^{6}$.

Desse modo, a produção independente surgiria como uma estratégia possível dentro da carreira do artista que, a princípio, não implicaria necessariamente num questionamento da indústria ou da sociedade como um todo. Mas Lelo Nazario, escrevendo para o mesmo jornal na semana seguinte, não interpreta as coisas desse modo. Para ele, os significados da produção independente são muito mais profundos, inscrevendo-se entre as formas de resistência a uma "sociedade industrial totalitária". Nesse sentido,

....arte independente é toda aquela que, partindo de uma nova ordem de valores que contrariam visceralmente os valores comerciais do sistema, pretende transformar aqueles que se dispõem a transformar a sociedade de armazém de mercadorias em um ambiente humano, onde as relações entre as pessoas não sejam mais regidas pelos interesses impostos de cima para baixo, mas

\footnotetext{
${ }^{5}$ Entre 1980 e 1985, a indústria manteve uma média de produção inferior a 45 milhões de unidades (contra 52.6 milhões registradas em 1979) e, embora tenha ocorrido alguma recuperação ao final da década, um crescimento realmente estável só seria verificado durante a segunda metade dos anos 90.

${ }^{6} \mathrm{O}$ disco independente, Folha de São Paulo, 14/03/1982
} 
pelos desejos autênticos dos indivíduos: os que suscitam a arte e a produzem 7 .

Mesmo entendendo as motivações de Nazario e considerando a importância do momento histórico então vivido pelo país, seria difícil não interpretar o surgimento da cena independente também como resultado da interiorização da racionalidade da indústria por parte dos artistas. São vários os argumentos a reforçar essa tese.

Em primeiro lugar, aquele apontado por Ziskind acerca da não existência de uma ligação clara entre a produção independente e a atuação de um grupo política e esteticamente coeso. Talvez tenha ocorrido, na verdade, a impressão de uma ligação, dada muito mais pelo espaço que um determinado grupo de criadores (vinculado, em grande parte, ao projeto do Lira Paulistana) ocupava junto à mídia escrita, do que propriamente pelo volume de sua produção. Vale ressaltar, sob esse aspecto, que nesse mesmo período a alternativa independente foi largamente utilizada também por artistas que atuavam em mercados regionais, na música sertaneja, na música instrumental e em outros segmentos ignorados pelas grandes gravadoras, sendo que até mesmo Emilinha Borba, ao sair da CBS em 1981, optou por essa forma de produção ${ }^{8}$.

Além disso, a atuação bem sucedida dentro do mercado independente parecia implicar num alto grau de compreensão dos aspectos envolvidos na produção e comercialização do disco. A esse respeito, Antônio Adolfo afirmava: “eu mesmo lanço e comercializo meus discos. Produzo a parte musical, faço a capa, mando prensar, mando imprimir e viajo por todo o Brasil, indo pessoalmente vender nas lojas o LP"'.

Outro fator a ser considerado é o de que nomes de maior destaque da cena independente, como Boca Livre e Oswaldo Montenegro, entre outros, aceitaram rapidamente os convites feitos por grandes gravadoras para integrar seus elencos.

\footnotetext{
${ }^{7}$ A mistificação dos discos independentes, Folha de São Paulo, 21/03/1982.

${ }^{8}$ Disco Independente S / A, Jornal do Brasil, 01/07/1981

9 O feito em casa em busca de um lugar, Folha de São Paulo, 28/10/1979. Outro aspecto enfatizado por Antônio Adolfo é o da necessidade do artista independente constituir uma empresa para viabilizar o lançamento de seu disco. No caso dele, essa empresa era a Indiscotível Discos e Fitas, a partir da qual seus discos eram lançados com o selo Artezanal. Como gravar sem restringir a criação, 07/07/1979.
} 
Isso me leva a considerar que a cena independente assumia também o papel de prospectar novos nichos de mercado e formar artistas para as grandes gravadoras, respondendo com maior precisão à crescente segmentação do público. Analisado sob esse aspecto, o projeto do Lira Paulistana parece-me exemplar.

O Teatro foi inaugurado na Vila Madalena, na cidade de São Paulo, no final de 1979 e polarizou, a partir de então, a cena e mesmo o debate sobre a produção musical independente no país. Iná Camargo Costa atribui a criação do projeto a um diagnóstico de Wilson Souto Jr (o Gordo), seu idealizador, acerca da "existência de um público insatisfeito com a produção cultural" formado principalmente por "estudantes universitários ou já graduados, mais ou menos atentos às transformações sociais (e políticas) porque vinha passando o país; um tanto quanto na vanguarda das assim chamadas mudanças de comportamento... mas com um detalhe bastante significativo: de baixo poder aquisitivo". Ao mesmo tempo, era considerada a existência de "uma produção cultural emergente, marginalizada pelos espaços institucionais e que vinha sobrevivendo em porões particulares, garagens e consumida apenas pelos amigos mais próximos”. Nesses termos, o Lira iria se constituir no "ponto fixo de encontro entre a nova produção e o público que a 'procurava"' (Costa, 1984: 34 e 35). Assim, a criação do teatro, da gráfica e do selo fonográfico (que ocorreria em 1981) corresponde a um cálculo das potencialidades do mercado em que se pretendia atuar.

Se até seu advento os nomes de destaque na cena eram os de Antônio Adolfo, Chico Mário, Boca Livre e Céu da Boca, entre outros, o Lira apresentou ao público um novo grupo formado por Arrigo Barnabé, Itamar Assumpção, Premeditando o Breque, Passoca e Língua de Trapo. Entre 1981 e 1982, o Lira serviria de palco também para bandas da emergente cena do rock nacional (como Titãs) e, ao final de 1982, iria se associar à tradicional gravadora Continental, onde o Gordo iniciaria uma nova carreira: primeiro como diretor artístico e, após a sua aquisição pela Warner (1994), como seu presidente.

De qualquer forma, e mesmo considerando a extraordinária importância artística e política de toda a cena, não seria difícil ficar com uma impressão de fracasso em relação ao 
projeto independente dos anos 80, já que muitas das iniciativas então desenvolvidas acabaram não tendo continuidade.

Em 1980, por exemplo, foi criado um departamento voltado para a produção de discos independentes dentro da Cooperativa dos Músicos Profissionais do Rio de Janeiro (Coomusa), que deveria encarregar-se da divulgação e distribuição dos trabalhos. Em 1981, porém, Antônio Adolfo considerava que a experiência não obtivera êxito devido à falta de estrutura financeira da cooperativa para, em função do próprio crescimento da cena independente, realizar com eficiência a distribuição nacional dos trabalhos ${ }^{10}$. Assim, acabou sendo criada em 16/05/1982 a APID - Associação dos Produtores Independentes de Discos. A Associação era presidida por Antônio Adolfo, tendo Chico Mário como vice. Chico afirmava existirem, por essa época, mais de 600 discos independentes no mercado, além de gravadoras como Kuarup (RJ), Bemol (MG), Som da Gente e Lira Paulistana (ambas de São Paulo) (Mário, 1986: 13). Mas na segunda metade da década, ambos decidiram que a associação deveria ter suas atividades paralisadas até que surgissem melhores condições para a sua atuação.

Finalmente, temos todo o projeto do Lira e, principalmente, sua associação à gravadora Continental. O projeto conjunto trazia uma série de inovações e previa, entre outras coisas, uma divisão mais equilibrada dos lucros, apoio para shows e para a obtenção de patrocínios, mapeamento dos espaços que poderiam sediar eventos em todo o país e a criação, em outros estados, de núcleos de aglutinamento da produção nos moldes do Lira, sendo as cidades de Porto Alegre, Belo Horizonte e Recife as escolhidas para o início desse projeto $^{11}$. A iniciativa conjunta, no entanto, jamais decolou e o projeto foi definitivamente abandonado em 1985, assim como as atividades do teatro (Oliveira, 2002: 96).

Seria fácil atribuir esse aparente fracasso à falta de uma visão mais comercial por parte dos artistas envolvidos no setor, às dificuldades de distribuição e divulgação enfrentadas pelos independentes, ao boicote das grandes companhias, etc. Em alguma medida, todos esses fatores provavelmente estiveram presentes. No entanto, eu entendo essa inviabilização de um projeto independente em maior escala muito mais como índice

${ }^{10}$ Disco Independente S/ A, Jornal do Brasil, 01/07/1981

${ }^{11}$ Lira Paulistana, o novo sócio da Continental, Folha de São Paulo, 28/11/1982 
da precariedade do capitalismo nacional como um todo do que enquanto resultado de fatores locais. A espiral inflacionária, o atraso tecnológico da indústria, as constantes mudanças nas regras econômicas e os problemas de fornecimento de matéria-prima, entre outros fatores, tornariam o cenário da segunda metade da década problemático até mesmo para o planejamento das grandes companhias do setor.

Nesse sentido, acho possível considerar que o projeto independente dos anos 80 esteve, num certo sentido, adiante das condições materiais que, nos anos 90, possibilitariam a sua definitiva implementação. O período de relativa estabilidade econômica do início do Plano Real e a dramática redução dos custos de produção oferecida pelas tecnologias digitais teriam um importante papel nesse processo, assim como a estratégia de terceirização da produção então adotada pelas grandes gravadoras.

\section{Os anos 1990}

Ao apresentar o cenário de uma indústria que, após a grande crise da Era Collor, iniciava em 1994 um processo que a levaria a uma significativa expansão ${ }^{12}$, a revista Backstage apontava que:

Terceirização é a palavra-chave quando falamos em estúdios e gravadoras. Há vinte anos atrás este quadro poderia ser loucura, com os altos preços dos equipamentos. Mas os preços baixaram, multiplicaram-se os estúdios e, com isso, as chances de acesso a gravação... O fechamento dos estúdios das grandes gravadoras começou com a diretiva das matrizes no exterior. A Warner Music, há cerca de 15 anos no Brasil, não chegou nem a ter o próprio estúdio... A EMI brasileira já teve três estúdios de primeira qualidade, mas agora optou pela terceirização... A BMG-Ariola encontrou uma solução diferente para seus 3 estúdios: eles foram repassados aos técnicos, que fazem prestação de serviços para a BMG quando necessário ${ }^{13}$.

Paralelamente, surgia um amplo leque de produtores e selos independentes que, em função da existência de empresas especializadas como estúdios, fábricas de CDs e firmas de editoração eletrônica, podiam operar a partir de estruturas cada vez mais

\footnotetext{
12 As vendas chegaram, em 1992, aos 32,1 milhões de unidades, patamar inferior ao de 1976. A partir da segunda metade da década de 90, no entanto, na esteira do Plano Real, a indústria viveria um momento de extraordinário crescimento. Suas vendas superariam os 100 milhões de unidades nos anos de 1997 e 1998 , colocando-a na sexta posição do ranking mundial do setor (IFPI, 1999: 67).

13 A terceirização da indústria, Revista Backstage n. 1, 1994, pág. 39.
} 
reduzidas. O selo Lux, por exemplo, criado por Nelson Motta em 1993, contava com apenas dois diretores e uma secretária e contratava os serviços especializados de terceiros para todas as suas necessidades. A empresa não tinha nem mesmo cast exclusivo, com "os

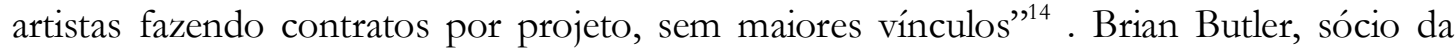
Excelente Discos, explicava em 1996 que "todo o processo de confecção dos discos da sua gravadora era feito por empresas parceiras: Somos só um escritório, o resto pode ser alugado".

É esse o contexto em que uma ressurgida cena independente mostra-se vigorosa o suficiente para substituir a grande indústria nas tarefas de prospecção, formação e gravação de novos artistas. Mas não foram apenas os fatores tecnológicos que propiciaram esse ressurgimento: também dessa vez a crise da indústria teve um papel decisivo: privilegiando desde o final dos anos 80 o sertanejo e a música romântica, além de severamente atingida pela recessão de 1990, a indústria demonstrava agora pouco interesse por segmentos como o rock e a MPB, ou por artistas que não fossem campeões de vendagem. Assim, em 1991, nomes como “Tim Maia, Tetê Spíndola, Quarteto em Cy, Belchior, Guinga, Hélio Delmiro e Vinícius Cantuária... só conseguiram gravar bancando o próprio trabalho" ${ }^{\text {,15. }}$ Paralelamente, de selos independentes de diferentes pontos do país começavam a surgir novos nomes do rap e do rock como Racionais MC's ('Zimbabwe), Raimundos (Banguela) e Sepultura (Cogumelo), entre outros.

Diferentemente do que ocorrera na década anterior, a oposição ideológica entre majors e indies, ou mesmo entre arte e mercado, pouco se fez presente em discursos e debates. Agora, parecia mais interessante aos empresários afirmar a profissionalização e viabilidade de seus investimentos. Para muitos deles, o conceito de selo independente no Brasil ainda estava, como declarou Pena Schmidt, da Tinitus, "muito associado à imagem do disco artesanal, praticado aqui nos anos 70" e concluía: "ser independente é apenas ser dono do próprio negócio"16. Assim, veteranos como Arrigo Barnabé, Eliete Negreiros e o Grupo Rumo, por exemplo, agora gravavam pelo selo independente Camerati, que

\footnotetext{
${ }^{14}$ Montar gravadora está mais barato, O Estado de São Paulo, 06/12/1996.

${ }^{15}$ Império dos independentes contra-ataca, O Estado de São Paulo, 13/02/1992

${ }^{16}$ Imagem ainda é 'artesanal', Folha de São Paulo, 06/01/1993.
} 
“masteriza e fabrica seus CDs nos EUA com supervisão do conceituado Toby Mountain,

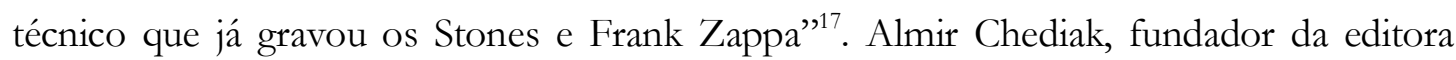
Lumiar e, posteriormente, da gravadora de mesmo nome, sintetizava a questão afirmando que "o importante nas produções independentes é que elas não tenham cara de independente" $" 18$.

Esse reforço da idéia da profissionalização evidenciava uma nova e mais pragmática relação entre independentes e mercado, uma compreensão compartilhada de sua lógica e realidade. E isso por duas importantes razões. Em primeiro lugar, muitos dos novos proprietários de gravadoras haviam saído dos quadros das majors, frequentemente descartados por políticas de contenção de custos e terceirização de atividades. Dentre os profissionais que saíram da Warner, criaram suas próprias empresas Pena Schmidt (Tinitus), Conie Lopes (Natasha Records) e Nelson Motta (Lux). Além deles, Mayrton Bahia, ex-Odeon e PolyGram, criou a Radical Records; Marcos Mazzola, ex-PolyGram, criou a MZA e Peter Klam, ex-diretor da Warner e da PolyGram, criou a Caju Music. Dentre os artistas que eram ou já haviam sido contratados de grandes gravadoras, criaram suas próprias empresas Ivan Lins (Velas), Dado Villa-Lobos (RockIt!), Marina Lima (Fullgás) e Ronaldo Bastos (Dubas), entre outros ${ }^{19}$.

Em segundo lugar, ocorria um intenso relacionamento entre majors e indies. Formas bem sucedidas de associação tornaram-se freqüentes e, em 1993, João Paulo Bandeira de Mello, diretor de marketing da EMI, descrevia a relação entre ela e os selos independentes que passara a distribuir como um dos pontos positivos da crise ${ }^{20}$.

Foram várias as indies que passaram a manter ou foram criadas a partir de relacionamentos com majors. Os contratos de distribuição eram - devido às dificuldades que essa área apresentava para as empresas menores - os mais freqüentes: a Caju Music e a Excelente Discos contavam com a distribuição da PolyGram; a Rock It, Radical, MP,B e Natasha tinham seus discos prensados e distribuídos pela EMI; a Warner cuidava da

\footnotetext{
${ }^{17}$ Idem, ibidem.

18 O som da liberdade, Jornal do Brasil, 20/02/1992.

${ }^{19}$ Independentes, porém pragmáticos, O Globo, 26/02/1997 e O som da liberdade, Jornal do Brasil, 20/02/1992.

${ }^{20}$ Chefões do disco vêem retomada das vendas, Folha de São Paulo, 10/05/1993.
} 
distribuição da Zimbabwe ${ }^{21}$, etc. Brian Butler, da Excelente, explicava inclusive que a Polygram, ao distribuir seus discos, acabava usando o selo como 'laboratório' de novas tendências ${ }^{22}$.

$\mathrm{E}$ de fato, formar artistas para posterior repasse às majors era uma perspectiva para vários empresários. Cacá Prates, sócio de Mayrton Bahia na Radical Records, considerava inclusive que a "tendência natural dos selos independentes é servir de fonte para as grandes gravadoras" ${ }^{\prime 23}$. Essas últimas, ao terceirizar suas atividades de produção, tendiam a se concentrar nas áreas de divulgação e distribuição, onde sua vantagem competitiva podia ser expressa através da extensão de sua estrutura logística, da facilidade de negociação com redes de supermercados e magazines, do acesso aos grandes grupos de comunicação e do potencial para a divulgação sinérgica de seus produtos.

Assim, é criada uma espécie de divisão do mercado, onde caberia às majors viabilizar a divulgação e distribuição maciça de alguns produtos pinçados da produção independente, que demonstrassem um maior potencial para transitar do circuito local para o nacional (ou mesmo mundial). Os independentes, nessa nova ordem, funcionavam basicamente como selos das grandes gravadoras, ou seja, como departamentos voltados à prospecção e ao atendimento de segmentos específicos.

Assim, se a produção independente tinha sido encarada nos anos 80 como alternativa ao ingresso do artista na grande gravadora, capaz de garantir uma maior autonomia para a sua criação, ela agora surgia como a única via de acesso às majors - espaço para que ele demonstre sua viabilidade comercial, adequação ao gosto do público e à lógica do mercado.

Mas esse não era o único incentivo para a produção independente. A grande segmentação da produção verificada a partir dos anos 90 relacionava-se, também, ao fortalecimento da produção cultural desenvolvida dentro daqueles que eu denomino como circuitos autônomos de produção musical, onde as fortes vinculações identitárias

\footnotetext{
${ }^{21}$ Caju e Kuarup resistem com lançamentos no exterior, O Estado de São Paulo, 13/02/1992; Montar gravadora está mais barato, O Estado de São Paulo, 06/12/1996; Selos alternativos dinamizam o mercado, Folha de São Paulo, 06/01/1993 e Selos pequenos crescem à margem da mídia, Folha de São Paulo, 15/07/1994.

22 Montar gravadora está mais barato, O Estado de São Paulo, 06/12/1996.

23 Selos pequenos crescem à margem da mídia, Folha de São Paulo, 15/07/1994.
} 
(comportamentais, geográficas, étnicas, religiosas, etc) e o acesso às tecnologias permitem a formação de uma rede de produção e distribuição cultural fora do âmbito das grandes gravadoras ou das redes nacionais de mídia. Foi a partir desses circuitos - de caráter local, mas quase sempre legitimados por referenciais internacionais-populares - que surgiu significativa parte não só do que foi realmente inovador na produção musical brasileiras das duas últimas décadas, como também alguns de seus maiores fenômenos de venda.

Gostaria de tomar como exemplo a cena do rock alternativo. Se o rock dos anos 80 era produzido predominantemente por jovens artistas brancos, de classe média, com formação universitária e oriundos de Brasília e de capitais do sul e do sudeste, ele ressurgia nos anos 90 a partir de uma configuração bem distinta: forte presença das periferias urbanas, principalmente de capitais do nordeste; influência importante da música negra, especialmente do funk e do rap - predominante em grupos como Rappa e Cidade Negra, entre outros; questionamentos sociais mais vigorosos e vinculação de algumas bandas a causas específicas (como a da legalização da maconha defendida, entre outros, pelo Planet Hemp).

O interesse das grandes gravadoras pelo segmento foi despertado já no início da década 90, com as majors criando ou se associando a selos voltados especificamente para a prospecção de novos artistas do cenário. O Banguela Records - que foi criado em 1994 através de uma associação entre Carlos Miranda, o grupos Titãs e a WEA - lançou as bandas brasilienses Raimundos, Little Quail e Mascavo Roots, além de Mundo Livre S/A (Recife) e Graforréia Xilarmônica (Porto Alegre). O selo Chaos, criado pela Sony em 1992, lançou nomes como Chico Science \& Nação Zumbi (Recife), Skank (Belo Horizonte), e Gabriel, o Pensador (Rio), entre outros. Também a BMG voltou-se para a cena através da reativação, em 1994, de seu selo Plug, criado ainda nos anos $80^{24}$.

Apesar dessas iniciativas, as majors acabaram dividindo a responsabilidade pelo surgimento dos novos nomes do pop/rock dos anos 90 com gravadoras independentes, a partir das quais foram lançadas bandas como Pato $\mathrm{Fu}$ (Cogumelo), contratada

\footnotetext{
24 Quando foram lançadas por ele bandas como Engenheiros do Hawaii, De Falla e Picassos Falsos. Alternativos dos 80 erraram no timing, Folha de São Paulo, 12/10/1993.
} 
posteriormente pela $\mathrm{BMG}^{25}$; Sepultura, que gravou pela Eldorado e pela Cogumelo; Rumbora e Sheik Tosado, que gravaram pela Trama, etc. As indies foram, ainda, responsáveis pelos primeiros lançamentos fonográficos de cenas como a do Forró Eletrificado de Fortaleza (SomZoom), do Boi de Parintins (Atração Fonográfica), do funk (Furacão 2000) e do rap (Kaskatas) que, posteriormente, também chegaram às majors.

De qualquer forma, a crise do final da década levou a um novo retraimento das grandes gravadoras e iniciativas como a dos selos Chaos, Plug e Banguela acabaram extintas, assim como muitas das atividades desenvolvidas em parceria.

\section{O cenário atual}

Assim como ocorrera nas décadas anteriores, também o final dos anos 90 foi marcado por uma crise. Se, em 1997, era apontada a possibilidade do Brasil, sexto mercado mundial, alcançar o quinto posto do ranking (França) em três ou quatro anos e, até 2020, ocupar o terceiro (Alemanha) ${ }^{26}$, a desvalorização cambial e a recessão econômica do final de 1998 modificaram totalmente as expectativas. Assim, no ano seguinte, a indústria apresentava queda de $8 \%$ no número de unidades vendidas, de $43 \%$ no faturamento em dólar e, em 2001, despencava para o $12^{\circ}$ lugar do ranking.

Além das questões gerais da economia, fatores específicos do setor também prejudicavam fortemente o desempenho da indústria. A pirataria era, sem dúvida, o mais importante deles. O problema não era novo no país, tendo atingido o mercado de fitas cassetes ainda nos anos 70. Em 1997, a ABPD estimava que o comércio de cassetes ilegais girava em torno de 60 milhões de unidades, contra menos de um milhão do comércio legal ${ }^{27}$. Atualmente, a APDIF (Associação Protetora dos Direitos Intelectuais Fonográficos), estima que a pirataria em CDs no país responde por mais de $50 \%$ do

\footnotetext{
25 Selos pequenos crescem à margem da mídia, Folha de São Paulo, 15/07/1994.

${ }^{26}$ CD, o objeto sonoro do desejo, Jornal do Brasil, 21/09/1997.

${ }^{27}$ Em 1998, a indústria praticamente abandonou o formato. No mercado de fitas cassetes, não há mais espaço para os produtos originais, O Estado de São Paulo, 19/07/1999. Vale ressaltar que, até pelo menos os anos iniciais da década de 2000, os cassetes ainda apresentavam uma vendagem significativa em outros países latinoamericanos e mesmo nos EUA.
} 
mercado, ao mesmo tempo em que a Federação Internacional da Indústria Fonográfica (IFPI) coloca o Brasil entre os dez países prioritários para a sua atuação anti-pirataria. ${ }^{28}$

Embora atinja também o mercado independente, a pirataria se mostra especialmente danosa para as majors, considerando que a estratégia do blockbuster tende a permitir uma maior concentração também das atividades dos produtores ilegais de CDs. Além da pirataria em formatos, temos também a distribuição ilegal de música pela internet. A IFPI estima em 20 bilhões o número de downloads ilegais de música realizados no mundo em 2005, sendo um bilhão deles atribuído ao Brasil. Mas as possibilidades de distribuição de música pela internet apontam, a meu ver, para algo bem mais importante do que a pirataria.

Por um lado, parecem demonstrar até o momento um relativo fracasso da grande indústria em controlar e transformar a distribuição digital no seu grande veículo de vendas. Afinal, a aproximação entre rede de distribuição digital e conteúdo - a versão mais recente da relação hardware/software - parece ter sido o grande impulsionador da fusão entre América On-Line e Time-Warner, ocorrida em janeiro de 2000, e para a união sob um mesmo conglomerado europeu da Universal (música, TV e cinema), do Canal Plus e do portal de internet Vizzavi, ocorrida em julho do mesmo ano. Por outro, a internet consolidou-se como alternativa consistente para a divulgação e distribuição dos trabalhos de artistas e gravadoras independentes, enfraquecendo o controle das majors sobre essas áreas vitais dentro de sua estratégia de atuação.

Assim, embora sedutora, a idéia das majors de se beneficiar do downsizing e do controle sobre novos segmentos e artistas possibilitados pela terceirização, ao mesmo tempo em que relançam seus catálogos para distribuição digital e concentram seus esforços no lançamento e venda de uns poucos blockbusters, parece colocada em cheque. O modelo se vê ameaçado até mesmo pelos artistas privilegiados por sua estratégia de concentração, sendo emblemático o exemplo de Prince, que rompeu seu contrato com a Warner ainda em 1994 partindo para a produção independente e a distribuição de seus trabalhos através

${ }^{28}$ www.apdif.org.br e IFPI Piracy Report In http://www.ifpi.org/content/library/PiracySummary. pdf . 
da internet. No processo, ele renunciou até mesmo o nome artístico com que fora promovido pela gravadora ${ }^{29}$.

Outro fator a corroborar a idéia de uma crise no modelo da indústria é o de que, apesar da crise geral do mercado fonográfico, é possível verificar nos últimos anos um nível inédito de reorganização da cena independente no país, com as indies passando a responder de forma praticamente exclusiva por uma série de segmentos de mercado como a música instrumental (Visom e Núcleo Contemporâneo), a música infantil (Palavra Cantada), a new age (MCD, Azul Music e Sonhos \& Sons), o choro (Acari Records), a MPB (Dubas e Biscoito Fino), o relançamento de gravações históricas (Revivendo), o rap (Sky Blue), o funk (Furacão 2000), o forró (SomZoom e MD Music) e a música religiosa (Paulinas, na música católica, Bom Pastor e Line Records, na evangélica), entre muitos outros.

Esses dois últimos segmentos, inclusive, chegaram a ter uma parada específica: realizada pelo Nopem e publicada por sua revista em seus últimos meses de existência. A última edição da revista, de agosto de 2002, mostrava as majors respondendo por apenas 4 dos 50 CDs de forró mais vendidos. Já na Parada Gospel, da mesma edição e voltada exclusivamente às produções do meio evangélico, o quadro era ainda mais radical, não sendo registrada a participação de nenhuma das grandes gravadoras ${ }^{30}$.

Além disso, também se consolidaram no cenário gravadoras de maior porte e atuação mais diversificada, que não apenas atuam em diferentes segmentos como, em alguns casos, também licenciam e distribuem discos de indies internacionais. Dentre essas empresas podemos citar Atração Fonográfica, Natasha, Trama, Deck Disc e Indie Records. Essas e outras indies contam, para a sua sustentação, também com as vendagens de artistas já consagrados que foram dispensados ou decidiram se afastar das grandes gravadoras. Esse é o caso de Alceu Valença (DeckDisc), Ed Motta e Gal Costa (Trama) e Chico

\footnotetext{
${ }^{29}$ Outro caso de ruptura unilateral de contrato opôs George Michael e sua gravadora, a Sony Music, ainda em 1993 (Burnett, 1996: 27).

${ }^{30}$ A Nopem, empresa especializada em pesquisas de mercado, foi criada em 1965. Sua revista foi publicada entre os anos de 1999 e 2002. As indies mais citadas na parada do forró foram SomZoom, CD Center e MD Music, além de produções de artistas independentes. Já na parada gospel, as principais citações foram para a MK Publicitá.
} 
Buarque e Maria Bethânia (Biscoito Fino), entre muitos outros. Entendo que pelo menos Trama e Biscoito Fino são gravadoras que já podem ter porte suficiente para justificar a designação de gravadoras médias, além de estarem vinculadas de alguma forma a grandes grupos econômicos (VR e Icatu, respectivamente).

Por todos esses fatores, vivemos um momento muito especial para o crescimento e a reorganização das indies. Além de algumas delas participarem atualmente da $\mathrm{ABPD}^{31}$, onde estão representadas todas as majors, a cena constituiu uma associação própria, a ABMI, Associação Brasileira de Música Independente, criada em 2002. Ela conta atualmente com aproximadamente 100 sócios e oferece, entre outros benefícios, contratos coletivos de distribuição digital, melhores condições de negociação com editoras (acerca dos direitos de regravação de músicas) e certificados de volume de vendas (discos de ouro, prata e platina $)^{32}$.

Assim, a indústria fonográfica brasileira vive na década atual um momento de contrastes. De um lado, sofre as conseqüências de uma crise que, envolvendo fatores como o quadro pouco alentador da economia, a pirataria digital e de formatos e talvez o próprio esgotamento de seu modelo, reduziu significativamente a sua importância econômica. De outro, vive um significativo processo de renacionalização e desconcentração da produção, potencialmente capaz de oferecer melhores condições para a expressão da real diversidade musical do país.

Não é um quadro simples. A retração da grande indústria cria grandes espaços vazios que, se não forem preenchidos pelas indies, podem determinar um esvaziamento da cena fonográfica do país e a redução das possibilidades de toda uma geração de artistas de estabelecer carreiras estáveis. Assim, entendo que a continuidade da crise e o agravamento do problema da pirataria colocam em risco toda a ecologia do mercado fonográfico. Em relação à pirataria, por exemplo, lembro que uma de suas conseqüências é o enfraquecimento das lojas especializadas - cuja substituição pelos grandes magazines como

\footnotetext{
${ }^{31}$ Caso de Paulinas-Comep, Sunshine, Indie Records e MK Publicitá.

32 www.abmi.com.br.
} 
pontos de vendas reduz tanto as possibilidades de distribuição dos independentes quanto de apresentação de novos artistas aos consumidores.

Além disso, entendo que o crescimento da cena independente impõe a necessidade de uma distinção mais clara entre os diferentes agentes que ocupam esse campo. Hoje, utilizamos a expressão "independente” para designar tanto o músico que produziu seu CD num home studio, quanto empresas como a Trama e a Biscoito Fino, criadas a partir de investimentos de milhões de reais. Compreender melhor essas diferenças talvez nos auxilie a ter uma visão mais clara das relações de força que parecem estar se estabelecendo no setor. Afinal, analisar o mercado a partir de uma divisão maniqueísta entre majors e indies nos levaria a ignorar o fato de que, também dentro de alguns dos circuitos autônomos, a concentração econômica se estabeleceu de maneira feroz. Já em 1998, por exemplo, a Revista Veja expunha alguns aspectos do funcionamento de circuitos como o da axé music e do forró eletrificado de Fortaleza. Segundo a matéria,

O grupo baiano Jheremias Não Bate Corner é um caso exemplar. No ano passado, seus três integrantes romperam com os empresários, o cantor Netinho e seu sócio, Misael Tavares. Detentores dos direitos sobre a marca, Netinho e Tavares contrataram outros artistas e montaram uma nova versão do Jheremias. A antiga banda teve de mudar seu nome para Jammil e Uma Noites. Essa nova forma de atuar permite aos empresários um lucro bem maior. A cada show, eles pagam aos artistas um cachê fixo, independentemente do valor recebido pela apresentação. O cearense Emanoel Gurgel, proprietário do Mastruz com Leite e de outros oito grupos de forró, tem hoje um império que inclui uma gravadora e uma rede de emissoras de rádio. Gurgel fatura 15 milhões de dólares por ano, enquanto alguns de seus músicos recebem 60 reais por show33.

De qualquer forma, o cenário dos circuitos autônomos ainda tem muito a nos oferecer em termos de análise. Tive oportunidade, durante meu doutorado, de descrever superficialmente alguns desses circuitos como os dos CTGs (Centros Populares de Cultura), do Forró de Fortaleza, do Rock Alternativo, da Axé Music, do rap, do funk e, de forma mais detalhada, o da música religiosa. Esse breve olhar reforçou minha convicção sobre a necessidade de se debruçar sobre esses e outros espaços de produção e consumo identificando não só suas relações de força, mas também sua segmentação interna (extremamente complexa em cenas como a do techno e do hardcore, por exemplo),

\footnotetext{
${ }^{33}$ Revista Veja 28/10/1998.
} 
instâncias de legitimação, circuito de exibição e estratégias de atuação dos artistas, entre muitos outros aspectos.

Esse tipo de análise ajudaria, entre outras coisas, a modificar a percepção do cenário musical brasileiro gerada pela atuação das grandes gravadoras que, ao catapultarem representantes de circuitos autônomos para o mainstream fonográfico, causam a impressão de que sua renovação ocorre a partir de artistas surgidos repentinamente de lugar nenhum. $\mathrm{Ou}$, por outro lado, geram uma visão reducionista dos circuitos, que tendem a ser definidos a partir das características dos seus artistas que a grande indústria decidiu promover ${ }^{34}$.

34 Como foi o caso do relacionamento automático de Bonde do Tigrão, Tati Quebra Barranco e congêneres com a cena funk carioca como um todo. 


\section{Bibliografia:}

BOURDIEU, Pierre. As Regras da Arte. São Paulo: Cia das Letras, 1996.

BURNETT, Robert, The Global Jukebox. London \& New York: Routledge, 1996

COSTA, I. C. Como se Tocaram as Cordas da Lira. In: Arte em Revista: Independentes, Ano 6, nº8, São Paulo: CEAC, 1984, p.34-36

FLICHY, P. Las Multinacionales del Audiovisual: Barcelona, Ed. Gustavo Gilli, 1982.

IDART. Disco em São Paulo, Damiano COZZELLA (Org.). São Paulo: Secretaria Municipal de Cultura/ Centro de Pesquisa de Arte Brasileira, 1980

IFPI, The Recording Industry in Numbers 2002: the definitive source of global music market information, London: IFPI. 2002

MÁRIO, Chico. Como Fazer um Disco Independente. Petrópolis, Vozes, 1986

OLIVEIRA, Laerte F. Em Um Porão de São Paulo: o Lira Paulistana e a Produção Alternativa. São Paulo: Fapesp/Annablume, 2002.

ORTIZ, Renato. Mundialização e Cultura. São Paulo, Brasiliense, 1994

TATIT, Luiz. Antecedentes dos Independentes. In: Arte em Revista. Independentes, Ano 6, nº8, São Paulo: CEAC, 1984, p.30-34

VICENTE, Eduardo. Música e Disco no Brasil tese de doutorado não publicada, São Paulo: ECA/USP, 2002. 